Review Article

\title{
Relationship between Subclinical Thyroid Dysfunction and the Risk of Cardiovascular Outcomes: A Systematic Review and Meta-Analysis of Prospective Cohort Studies
}

\author{
Jing Sun, ${ }^{1}$ Liang Yao, ${ }^{2}$ Yuan Fang, ${ }^{1}$ Ruifei Yang, ${ }^{1}$ Yaolong Chen, ${ }^{3}$ Kehu Yang, ${ }^{3}$ and \\ Limin Tian ${ }^{1}$ \\ ${ }^{1}$ Department of Endocrinology, Gansu Provincial Hospital, Dong Gang West Road, Lanzhou, Gansu 730000, China \\ ${ }^{2}$ Clinical Evidence-Based Medicine Center, Gansu Provincial Hospital, Dong Gang West Road, Lanzhou, Gansu 730000, China \\ ${ }^{3}$ Evidence-Based Medicine Center, School of Basic Medical Sciences, Lanzhou University, Lanzhou 730000, China
}

Correspondence should be addressed to Kehu Yang; yangkhebm2006@126.com and Limin Tian; 13893416703@163.com

Received 23 February 2017; Revised 28 May 2017; Accepted 15 June 2017; Published 31 August 2017

Academic Editor: Mario Maggi

Copyright ( 2017 Jing Sun et al. This is an open access article distributed under the Creative Commons Attribution License, which permits unrestricted use, distribution, and reproduction in any medium, provided the original work is properly cited.

\begin{abstract}
Background. Evidence on the association between subclinical thyroid dysfunction and the risk of cardiovascular outcomes are conflicting. Methods and Results. PubMed, EMbase, Web of Science, Cochrane Library, and China Biology Medicine (CBM) databases were searched from inception to July 10, 2016. A total of 16 studies were included for meta-analysis. We found that subclinical hypothyroidism was not correlated with coronary heart disease (CHD) $(\mathrm{RR}=1.17 ; 95 \% \mathrm{CI}, 0.91-1.52)$, total mortality $(\mathrm{RR}=1.02 ; 95 \% \mathrm{CI}, 0.93-1.13)$, cardiovascular mortality $(\mathrm{RR}=1.06 ; 95 \% \mathrm{CI}, 0.77-1.45)$, heart failure $(\mathrm{RR}=1.17 ; 95 \%$ $\mathrm{CI}, 0.87-1.57)$, and atrial fibrillation $(\mathrm{RR}=1.05$; 95\% CI, 0.91-1.21), except CHD mortality $(\mathrm{RR}=1.37$; 95\% CI, 1.03-1.84). Subgroup analysis indicated a higher estimation risk in $\mathrm{CHD}(\mathrm{RR}=1.54 ; 95 \% \mathrm{CI}, 1.00-2.39)$, cardiovascular mortality $(\mathrm{RR}=2.14 ; 95 \% \mathrm{CI}, 1.43-3.22)$, and $\mathrm{CHD}$ mortality $(\mathrm{RR}=1.54 ; 95 \% \mathrm{CI}, 1.11-2.15)$ among participants $<65$ years. Furthermore, subclinical hyperthyroidism was found to be associated with $\mathrm{CHD}$ (RR $=1.20$; 95\% CI, 1.02-1.42), total mortality $(\mathrm{RR}=1.27 ; 95 \% \mathrm{CI}, 1.07-1.51)$, and CHD mortality $(\mathrm{RR}=1.45 ; 95 \% \mathrm{CI}, 1.12-1.86)$. Conclusions. Subclinical hypothyroidism is likely associated with an increased risk of CHD mortality, and subclinical hyperthyroidism is likely associated with increased risk of CHD, CHD mortality, and total mortality.
\end{abstract}

\section{Introduction}

Subclinical thyroid dysfunction (SCTD) is defined as an abnormal serum thyroid-stimulating hormone (TSH) level, with normal concentrations of free thyroxine (T4) and free triiodothyronine (T3) $[1,2]$. The prevalence of SCTD was high in the general population: $3.1 \sim 8.5 \%$ among patients with subclinical hypothyroidism [3] and 1 10\% among those with subclinical hyperthyroidism [4-7]. Subclinical hypothyroidism is more common than subclinical hyperthyroidism [8]. However, early screening and treatment of SCTD are still controversial on the basis of current evidence $[1,8]$.
The cardiovascular system is one of the main target organs of thyroid hormones [9], and elevated or decreased TSH levels can adversely affect the cardiovascular system $[10,11]$. Some studies demonstrated that subclinical hypothyroidism increased cardiovascular risk factors including altered lipid profile [12], insulin resistance [13], oxidative stress [14], increased vascular stiffness [15], and endothelial dysfunction [16]. Subclinical hyperthyroidism also manifested in the cardiovascular system by numerous ways, including increased heart rate [17], left ventricular mass [18], susceptibility to endothelial dysfunction [19], and left ventricular diastolic dysfunction [20], which can cause changes in cardiovascular morphology and function. 


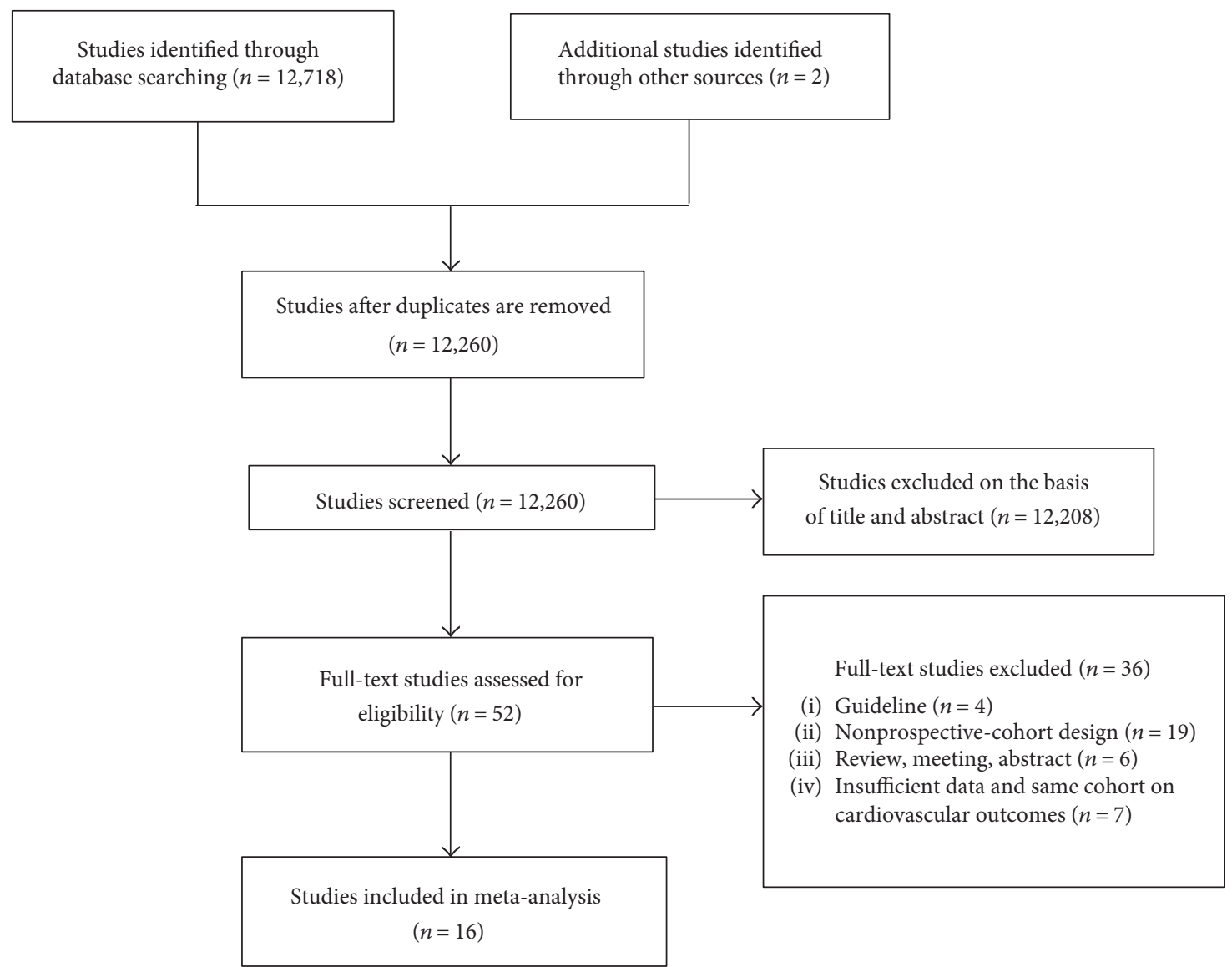

Figure 1: Flow chart for study inclusion.

However, there is conflicting evidence regarding the association between coronary heart disease (CHD) and mortality [5, 21-24]. Although several meta-analyses had been published, they included studies prior to 2011 and revealed conflicting findings [25-30]. In recent years, several prospective cohort studies with a large sample size have been published in peer-reviewed journals [21, 31-35], which may change findings of previous meta-analyses. So it is necessary to conduct a new meta-analysis to explore the relationship between SCTD and the risk of cardiovascular outcomes to provide more rigorous and credible evidence for the clinical decision related to SCTD.

\section{Material and Methods}

2.1. Search Strategy. We systematically searched PubMed, EMbase, Web of Science, Cochrane Library, and China Biology Medicine (CBM) databases for target studies from inception to July 10, 2016, without language restriction. The search strategy was conducted by medical subject headings (thyroid diseases, hypothyroidism, hyperthyroidism, thyrotropin, thyroid hormones, myocardial ischemia, mortality, survival, heart failure, atrial fibrillation, and cardiovascular diseases) and with text words (subclinical hypothyroidism, subclinical hyperthyroidism, subclinical dysthyroidism, and subclinical thyroid). In addition, we also searched the references of included articles to expand the search.
2.2. Study Selection. Two reviewers (Jing Sun and Ruifei Yang) independently screened the abstracts and titles of the searched articles according to the inclusion criteria: (1) reported diagnostic criteria for SCTD; (2) must be full-text prospective cohort study; (3) at least reported one cardiovascular outcome; (4) and compared with euthyroidism. The following articles were excluded: (1) studies including only overt thyroid dysfunction or lacking a report on SCTD diagnostic criteria; (2) case series or reviews and conference abstracts; (3) raw data could not be extracted; (4) and similar studies were reported without additional data to analyze and extract.

2.3. Data Extraction. Two reviewers (Jing Sun and Ruifei Yang) independently extracted data on participant characteristics from the selected studies in a standardized data extraction form. We extracted the following information from each included article: the name of the first author, year of publication, number of participants, mean followup duration, participant characteristics, baseline of thyroid function and cardiovascular risk factors (e.g., smoking, diabetes, blood pressure, and low- and high-density lipoprotein cholesterol level), (thyroid) medication use at baseline, and outcome data.

2.4. Methodological Quality Assessment of Included Studies. Methodological quality assessment was performed in 
TABLE 1: Baseline characteristics of subclinical thyroid dysfunction in included studies.

\begin{tabular}{|c|c|c|c|c|c|c|c|}
\hline First author, year & Sample & $\begin{array}{l}\text { Mean age } \\
\text { (range) }(y)\end{array}$ & Follow-up & $\begin{array}{c}\text { TSH cutoff } \\
\text { value (mIU/L) } \\
\text { (Shypo/Shyper) }\end{array}$ & $\begin{array}{c}\text { Thyroxine } \\
\text { measured } \\
\text { (Shypo/Shyper) }\end{array}$ & $\begin{array}{l}\text { Exclusion of } \\
\text { thyroid hormone/ } \\
\text { antithyroid } \\
\text { drug recipients }\end{array}$ & $\begin{array}{c}\text { Outcome } \\
\text { (Shypo or Shyper) }\end{array}$ \\
\hline Parle et al. [43] & 1187 & $70.4(>60)$ & $8.2 \mathrm{y}$ & $>5.0 /<0.44$ & Yes/yes & Yes/yes & $\begin{array}{c}\text { CHD, CHD mortality, } \\
\text { total, and cardiovascular } \\
\text { mortality }\end{array}$ \\
\hline Gussekloo et al. [42] & 527 & 85 & $3.7 \mathrm{y}$ & $>4.8 /<0.3$ & Yes/yes & Yes/yes & $\begin{array}{l}\text { CHD, CHD mortality, } \\
\text { total, and cardiovascular } \\
\text { mortality }\end{array}$ \\
\hline Rodondi et al. [41] & 2730 & $74.7(70-79)$ & $4 y$ & $\geq 4.5 / \mathrm{NA}$ & Yes/NA & NR/NA & $\begin{array}{l}\mathrm{CHD}, \mathrm{HF} \text {, total, and } \\
\text { cardiovascular mortality }\end{array}$ \\
\hline Walsh et al. [24] & 1890 & $49.8(17-89)$ & $20 \mathrm{y}$ & $>4.0 /<0.4$ & Yes/yes & NR/NR & $\begin{array}{c}\text { CHD and cardiovascular } \\
\text { mortality }\end{array}$ \\
\hline Cappola et al. [23] & 3182 & $72.7(\geq 65)$ & $12.5 \mathrm{y}$ & $>4.5 /<0.45$ & Yes/yes & Yes/yes & $\begin{array}{l}\mathrm{CHD}, \mathrm{AF} \text {, total, and } \\
\text { cardiovascular mortality }\end{array}$ \\
\hline Bauer et al. [40] & 487 & $71.7(\geq 65)$ & $11.9 \mathrm{y}$ & $>5.5 / \leq 0.5$ & NR/NR & NR/NR & $\begin{array}{c}\text { Total and cardiovascular } \\
\text { mortality }\end{array}$ \\
\hline Rodondi et al. [39] & 3044 & $72.6(\geq 65)$ & $15 y$ & $>4.5 /<0.45$ & Yes/yes & Yes/yes & $\mathrm{HF}$ \\
\hline Razvi et al. [38] & 2350 & $45.4(18-92)$ & $20 \mathrm{y}$ & $>6 / \mathrm{NA}$ & NR/NA & Yes/NA & $\begin{array}{l}\text { CHD, CHD mortality, } \\
\text { and total mortality }\end{array}$ \\
\hline Boekholdt et al. [5] & 13,141 & $58(45-79)$ & $10.6 \mathrm{y}$ & $>4 /<0.4$ & Yes/yes & Yes/yes & $\begin{array}{l}\text { CHD, CHD mortality, } \\
\text { and total mortality }\end{array}$ \\
\hline Ittermann et al. [44] & 3883 & $48.9(20-79)$ & $8.5 \mathrm{y}$ & $\mathrm{NA} /<0.25$ & NA/yes & NA/yes & $\begin{array}{l}\mathrm{CHD}, \mathrm{CHD} \text { mortality, } \\
\mathrm{AF} \text {, and total mortality }\end{array}$ \\
\hline Jongh et al. [21] & 1197 & $75.5(>65)$ & $10.7 \mathrm{y}$ & $>4.5 /<0.3$ & Yes/yes & Yes/yes & $\begin{array}{l}\mathrm{CHD}, \mathrm{CHD} \text { mortality, } \\
\text { total, and cardiovascular } \\
\text { mortality }\end{array}$ \\
\hline Schultz et al. [35] & 605 & $67.8(50-91)$ & $5 y$ & $>4 /<0.4$ & Yes/yes & NR/NR & Total mortality \\
\hline Nanchen et al. [33] & 5316 & $75(70-82)$ & $3.2 \mathrm{y}$ & $\geq 4.5 /<0.45$ & Yes/yes & Yes/yes & $\begin{array}{l}\mathrm{CHD}, \mathrm{HF}, \mathrm{AF} \text {, total, and } \\
\text { cardiovascular mortality }\end{array}$ \\
\hline Asvold et al. [34] & 26,475 & 53.7 & $12.3 \mathrm{y}$ & $>3.6 /<0.49$ & Yes/yes & NR/NR & $\begin{array}{c}\mathrm{CHD}, \mathrm{CHD} \text { mortality, } \\
\text { and HF }\end{array}$ \\
\hline Ceresini et al. [32] & 931 & $75.5(>65)$ & $6 y$ & $>4.68 /<0.49$ & Yes/yes & Yes/yes & Total mortality \\
\hline Hyland et al. [31] & 4863 & $73.5(>65)$ & $10 \mathrm{y}$ & $>4.5 / \mathrm{NA}$ & Yes/NA & NR/NA & $\begin{array}{l}\mathrm{CHD} \text {, cardiovascular } \\
\text { mortality, and HF }\end{array}$ \\
\hline
\end{tabular}

Shypo: subclinical hypothyroidism; Shyper: subclinical hyperthyroidism; CHD: coronary heart disease; AF: atrial fibrillation; HF: heart failure; TSH: thyroidstimulating hormone; NR: not reported; NA: not applicable (because the outcome was not examined in the study).

accordance with the Newcastle-Ottawa Quality Assessment Scale (NOS), which is a validated scale for nonrandomized studies in meta-analyses [36]. In this analysis, studies that received $\geq 7$ points were considered of high methodological quality. Besides, we assessed some other items to evaluate the methodological quality of included studies: (1) whether the study was population based; (2) whether the study had formal adjudication procedures, which were defined as having clear outcome criteria that were reviewed by experts for each potential case; (3) whether the adjudication was performed without knowledge of thyroid status; and (4) the adjustments for multivariate analysis.

2.5. Quality of the Evidence Assessment. We assessed the quality of evidence for each outcome using the Grading of Recommendations Assessment, Development and Evaluation (GRADE) criteria [37]. We rated the quality of evidence, starting at high quality and downgrading for the risk of bias, imprecision, inconsistency, indirectness, and publication bias. In this meta-analysis, we present "Summary of findings" table using the following primary outcomes: (1) CHD, (2) total mortality, (3) cardiovascular mortality, (4) CHD mortality, (5) heart failure, and (6) atrial fibrillation.

2.6. Data Synthesis and Statistical Analysis. In this metaanalysis, risk ratio (RR) and $95 \%$ confidence interval (CI) were considered as the effect size for all studies. Forest plots were produced to visually assess the RR and corresponding 95\% CI using random-effects models. In addition, we also conducted a fixed-effects model for comparison. Heterogeneity between studies was assessed via the forest plot, while $I^{2}$ values described the total variation between studies. $I^{2}$ values of $<25 \%, 25 \%-50 \%$, and $>50 \%$ indicated low, moderate, and high heterogeneity, respectively. We used sensitivity 


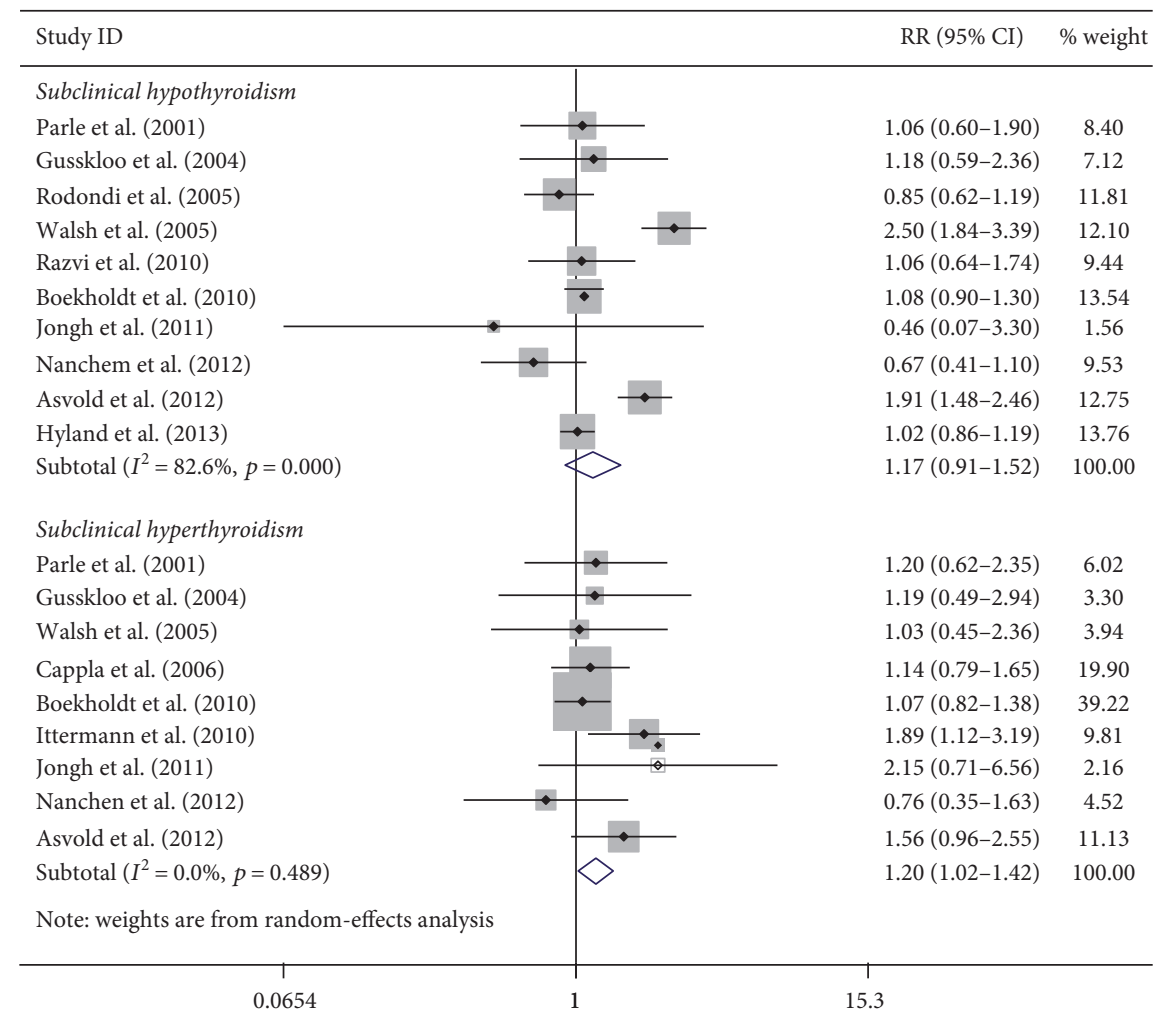

(a)

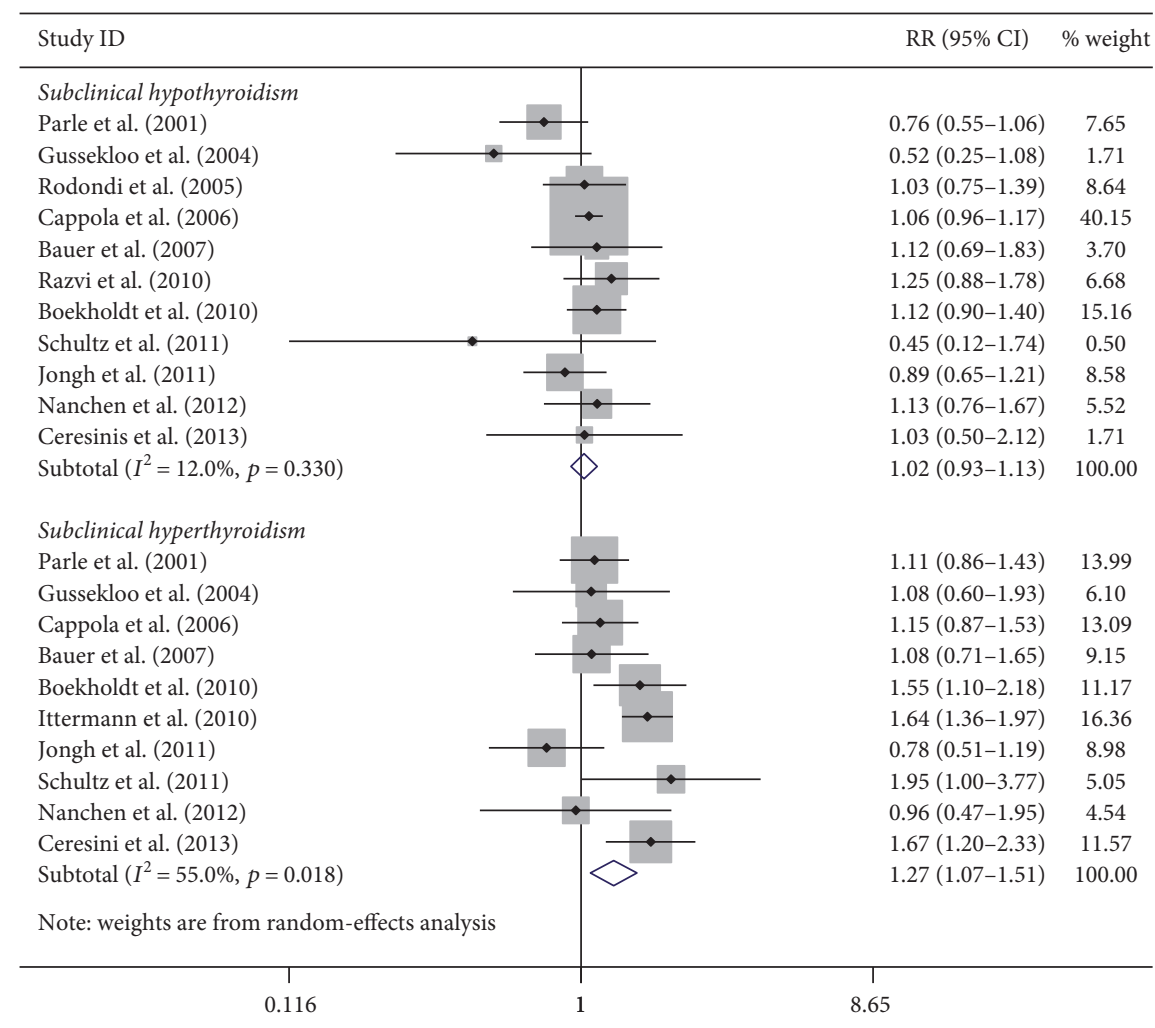

(b)

Figure 2: Continued. 


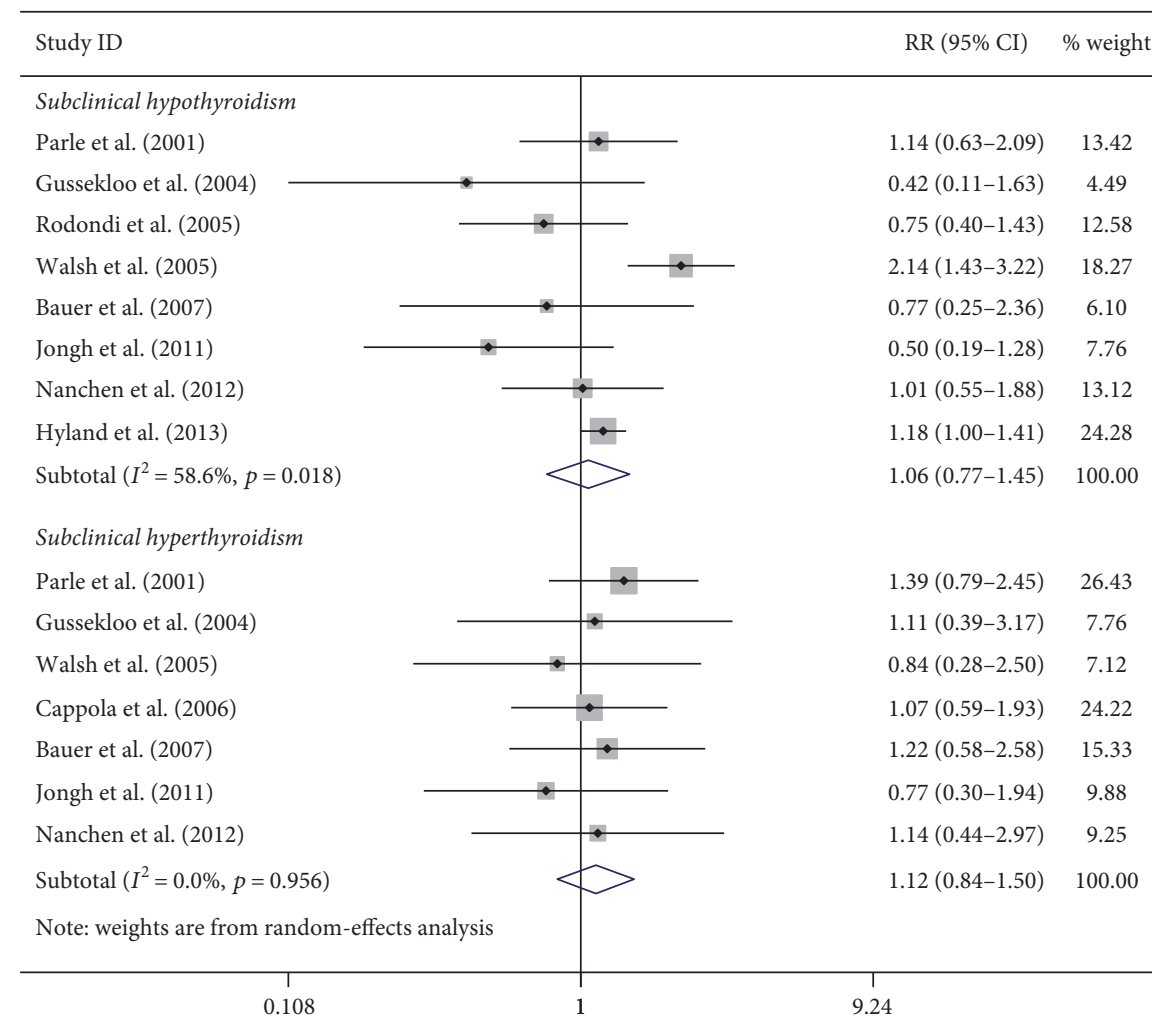

(c)

FIgURE 2: Forest plots for subclinical thyroid dysfunction. (a) Forest plots for subclinical thyroid dysfunction and risk of CHD; (b) forest plots for subclinical thyroid dysfunction and risk of total mortality; (c) forest plots for subclinical thyroid dysfunction and risk of cardiovascular mortality.

and subgroup analyses to explore and interpret the sources of high heterogeneity. We explored the relationship of SCTD and cardiovascular outcomes among participants of different age groups ( $<65$ years or $\geq 65$ years and $<60$ years, 60-79.9 years, or $\geq 80$ years) and different TSH levels (4.5-9.9 $\mathrm{mIU} / \mathrm{L}$ or $10-19.9 \mathrm{mIU} / \mathrm{L})$. Statistical analysis was performed with STATA software, version 12.0 (StataCorp, College Station, TX).

\section{Results}

3.1. Study Selection. A total of 12,720 studies initially identified, and 12,260 remained after excluding duplicate citations. 12,208 studies were excluded by title and/or abstract not related to the research topic, and 36 studies were excluded by full-text screening. Finally, 16 studies that met the eligibility criteria were included for further analysis. The literature screening process is shown in Figure 1.

3.2. Characteristics and Quality of Included Studies. Table 1 shows the characteristics of included studies in our metaanalysis. A total of 71,808 participants were included in the 16 studies, of which 5178 were defined as having subclinical hypothyroidism (7.2\%), 64,330 with euthyroidism (89.6\%), and 2300 with subclinical hyperthyroidism (3.2\%). 15 studies reported an association between subclinical hypothyroidism and cardiovascular outcomes [5, 21, 23, 24, 31-35, 38-43], and 13 reported an association between subclinical hyperthyroidism and cardiovascular outcomes [5, 21, 23,24, 32-35, 39, 40, 42-44]. Most of the participants were middle aged or elderly (aged 45.4-85 years), and the follow-up duration of the included studies ranged from 3.2 to 20 years. All studies were population based, and seven studies reported adjudication without knowledge of thyroid status (Supplemental Material Table 1 available online at https:/doi.org/10.1155/ 2017/8130796). Based on the NOS results, the studies showed similar scores overall but scored differently on the separate item (Supplemental Material Table 2). The TSH cutoff values were controversial in different studies, ranging from 4.0$6.0 \mathrm{mIU} / \mathrm{L}$ in subclinical hypothyroidism and $0.3-0.5 \mathrm{mIU} / \mathrm{L}$ in subclinical hyperthyroidism.

\subsection{Main Results}

3.3.1. Subclinical Thyroid Dysfunction and CHD. Ten studies [5, 21, 24, 31, 33, 34, 38, 41-43] (4979 CHD events) reported a relationship between subclinical hypothyroidism and CHD (Figure 2(a)). The pooled RR was 1.17 (95\% CI, $0.91-1.52)$, and the heterogeneity was high $(p<0.01$, $\left.I^{2}=82.6 \%\right)$. Risk was similar after adjusting cardiovascular risk factors (Table 2). Heterogeneity was reduced by excluding studies that included thyroid hormone recipients $\left(p=0.68, I^{2}=0.0 \%\right)$. 
TABLE 2: Stratified and sensitivity analysis of the subclinical hypothyroidism.

\begin{tabular}{|c|c|c|}
\hline Subclinical hypothyroidism and CHD & Summary relative risk $(95 \% \mathrm{CI})^{+}$ & Studies, $n$ \\
\hline \multicolumn{3}{|l|}{ Eligible study model } \\
\hline Random effects & $1.17(0.91-1.52)$ & 10 \\
\hline Fixed effects & $1.14(1.04-1.25)$ & 10 \\
\hline \multicolumn{3}{|l|}{ Stratified by mean age, y } \\
\hline$<65$ & $1.54(1.00-2.39)$ & 4 \\
\hline$\geq 65$ & $0.96(0.84-1.10)$ & 6 \\
\hline$<60$ & $1.54(1.00-2.39)$ & 4 \\
\hline $60-79.9$ & $0.96(0.84-1.09)$ & 5 \\
\hline$\geq 80$ & $1.18(0.59-2.36)$ & 1 \\
\hline \multicolumn{3}{|l|}{ Stratified by TSH, mIU/L } \\
\hline $4.5-9.9$ & $1.07(0.67-1.70)$ & 4 \\
\hline $10-19.9$ & $1.38(0.68-2.78)$ & 4 \\
\hline $4.5-6.9$ & $0.99(0.84-1.17)$ & 2 \\
\hline $7.0-9.9$ & $0.92(0.66-1.27)$ & 2 \\
\hline \multicolumn{3}{|l|}{ Adjustments } \\
\hline Adjusted analyses or matching & $1.17(0.91-1.52)$ & 10 \\
\hline Adjusted for cardiovascular risk factors & $1.09(0.71-1.65)$ & 6 \\
\hline \multicolumn{3}{|l|}{ Excluding studies } \\
\hline Exclusion of studies with thyroid hormone recipients & $1.02(0.92-1.14)$ & 7 \\
\hline Exclusion of studies with particular population [42] & $1.17(0.89-1.54)$ & 9 \\
\hline Subclinical hypothyroidism and total mortality & Summary relative risk $(95 \% \mathrm{CI})^{+}$ & Studies, $n$ \\
\hline \multicolumn{3}{|l|}{ Eligible study model } \\
\hline Random effects & $1.02(0.93-1.13)$ & 11 \\
\hline Fixed effects & $1.03(0.95-1.11)$ & 11 \\
\hline \multicolumn{3}{|l|}{ Stratified by mean age, y } \\
\hline$<65$ & $1.16(0.96-1.40)$ & 2 \\
\hline$\geq 65$ & $0.98(0.87-1.10)$ & 9 \\
\hline$<60$ & $1.16(0.96-1.40)$ & 2 \\
\hline $60-79.9$ & $1.02(0.94-1.11)$ & 8 \\
\hline$\geq 80$ & $0.52(0.25-1.08)$ & 1 \\
\hline \multicolumn{3}{|l|}{ Stratified by TSH, mIU/L } \\
\hline $4.5-9.9$ & $1.05(0.80-1.36)$ & 2 \\
\hline $10-19.9$ & $1.25(0.67-2.36)$ & 2 \\
\hline $4.5-6.9$ & $0.92(0.62-1.35)$ & 1 \\
\hline $7.0-9.9$ & $1.06(0.55-2.04)$ & 1 \\
\hline \multicolumn{3}{|l|}{ Adjustments } \\
\hline Adjusted analyses or matching & $1.02(0.93-1.13)$ & 11 \\
\hline Adjusted for cardiovascular risk factors & $1.06(0.97-1.15)$ & 5 \\
\hline \multicolumn{3}{|l|}{ Excluding studies } \\
\hline Exclusion of studies with thyroid hormone recipients & $1.01(0.90-1.15)$ & 8 \\
\hline Exclusion of studies with particular population [42] & $1.04(0.97-1.13)$ & 10 \\
\hline Subclinical hypothyroidism and cardiovascular mortality & Summary relative risk $(95 \% \mathrm{CI})^{+}$ & Studies, $n$ \\
\hline \multicolumn{3}{|l|}{ Eligible study model } \\
\hline Random effects & $1.06(0.77-1.45)$ & 8 \\
\hline Fixed effects & $1.13(0.98-1.30)$ & 8 \\
\hline \multicolumn{3}{|l|}{ Stratified by mean age, $\mathrm{y}$} \\
\hline$<65$ & $2.14(1.43-3.22)$ & 1 \\
\hline$\geq 65$ & $1.00(0.79-1.26)$ & 7 \\
\hline
\end{tabular}


TABLE 2: Continued.

\begin{tabular}{lll}
\hline$<60$ & $2.14(1.43-3.22)$ & 1 \\
$60-79.9$ & $1.08(0.90-1.29)$ & 6 \\
$\geq 80$ & $0.42(0.11-1.63)$ & \\
Stratified by TSH, mIU/L & $1.03(0.73-1.45)$ & 1 \\
$4.5-9.9$ & $1.25(0.81-1.95)$ & 3 \\
$10-19.9$ & $0.83(0.31-2.21)$ & 2 \\
$4.5-6.9$ & $1.06(0.73-1.54)$ & \\
$7.0-9.9$ & & \\
Adjustments & $1.06(0.77-1.45)$ \\
Adjusted analyses or matching & $1.02(0.52-2.00)$ \\
Adjusted for cardiovascular risk factors & & 4 \\
Excluding studies & & \\
Exclusion of studies with thyroid hormone recipients & $0.86(0.56-1.32)$ \\
Exclusion of studies with particular population $[42]$ & $1.11(0.81-1.52)$ \\
\hline
\end{tabular}

CHD: coronary heart disease; TSH: thyroid-stimulating hormone. ${ }^{+}$Relative risk from meta-analysis using random-effects model.

Nine studies [5, 21, 23, 24, 33, 34, 42-44] (4116 CHD events) demonstrated the relationship between subclinical hyperthyroidism and CHD (Figure 2(a)). The result of meta-analysis showed a significant association $(R R=1.20$; 95\% CI, 1.02-1.42), and no heterogeneity was found ( $\left.p=0.49, I^{2}=0 \%\right)$. However, no significant result was found after adjusting cardiovascular risk factors and excluding studies with antithyroid drug recipients (Table 3 ).

3.3.2. Subclinical Thyroid Dysfunction and Total Mortality. No significant association was found in total mortality and subclinical hypothyroidism $(\mathrm{RR}=1.02 ; 95 \% \mathrm{CI}, 0.93-1.13)$, and the result was pooled from eleven studies [5, 21, 23, 32, 33, 35, 38, 40-43] (Figure 2(b)). Sensitivity analyses yielded similar results after excluding studies without adjusting analysis for cardiovascular risk factors, studies with a particular population (mean age $\geq 80$ years), and studies containing thyroid hormone recipients (Table 2).

For subclinical hyperthyroidism, the pooled result showed an increased total mortality $(R R=1.27 ; 95 \% \mathrm{CI}$, 1.07-1.51) based on ten studies $[5,21,23,32,33,35,40$, 42-44] (Figure 2(b)). Risk was similar after excluding thyroid hormone recipients (Table 3 ).

3.3.3. Subclinical Thyroid Dysfunction and Cardiovascular Mortality. Eight studies [21, 24, 31, 33, 40-43] (1755 cardiovascular mortality events) reported a relationship between subclinical hypothyroidism and cardiovascular mortality (Figure 2(c)). We found that subclinical hypothyroidism was not significantly associated with cardiovascular mortality $(\mathrm{RR}=1.06 ; 95 \% \mathrm{CI}, 0.77-1.45)$. Risk was similar after adjusting cardiovascular risk factors (Table 2).

Seven studies $[21,23,24,33,40,42,43]$ (1347 cardiovascular mortality events) reported the relationship between subclinical hyperthyroidism and cardiovascular mortality (Figure 2(c)). The pooled RR for cardiovascular mortality was 1.12 (95\% CI, 0.84-1.50), without heterogeneity $\left(p=0.10, I^{2}=0.0 \%\right)$. Most sensitivity analyses yielded similar results (Table 3 ).

3.3.4. Subclinical Thyroid Dysfunction and CHD Mortality. Compared with euthyroidism, subclinical hypothyroidism was associated with $\mathrm{CHD}$ mortality $(\mathrm{RR}=1.37 ; 95 \% \mathrm{CI}$, 1.03-1.84) based on six studies [5, 21, 34, 38, 42, 43] (1369 CHD mortality events) (Figure 3(a)). No statistical association was found between subclinical hypothyroidism and CHD mortality after adjusting cardiovascular risk factors and excluding studies included antithyroid drug recipients (Table 4 ).

We found that subclinical hyperthyroidism was associated with $\mathrm{CHD}$ mortality $(\mathrm{RR}=1.45 ; 95 \% \mathrm{CI}, 1.12-1.86)$ based on six studies [5, 21, 34, 42-44] (1263 CHD mortality events) (Figure 3(a)). Sensitivity analyses yielded similar results after excluding studies without further adjustment analysis for cardiovascular risk factors, studies with a particular population (mean age $\geq 80$ years), and studies including antithyroid drug recipients (Table 4).

3.3.5. Subclinical Thyroid Dysfunction, Heart Failure, and Atrial Fibrillation. Among participants with subclinical hypothyroidism, there happened 1704 heart failure events with pooled RR of 1.17 (95\% CI, 0.87-1.57) and 1339 atrial fibrillation events with pooled RR of 1.05 (95\% CI, 0.911.21) (Figures 3(b) and 3(c)).

For subclinical hyperthyroidism, there happened 1200 heart failure events with pooled RR of 1.54 (95\% CI, $0.87-$ 2.71) and 1240 atrial fibrillation events with pooled RR of 1.42 (95\% CI 0.69-2.92) (Figures 3(b) and 3(c)).

3.3.6. Subgroup Analysis. Subgroup analyses about the association between subclinical thyroid dysfunction and CHD, CHD mortality, cardiovascular mortality, and total mortality in different age and TSH levels were shown in Tables 2-4. 
TABLE 3: Stratified and sensitivity analysis of the subclinical hyperthyroidism.

\begin{tabular}{|c|c|c|}
\hline Subclinical hyperthyroidism and CHD & Summary relative risk $(95 \% \mathrm{CI})^{+}$ & Studies, $n$ \\
\hline \multicolumn{3}{|l|}{ Eligible study model } \\
\hline Random effects & $1.20(1.02-1.42)$ & 9 \\
\hline Fixed effects & $1.20(1.02-1.41)$ & 9 \\
\hline \multicolumn{3}{|l|}{ Stratified by mean age, y } \\
\hline$<65$ & $1.32(0.98-1.77)$ & 4 \\
\hline$\geq 65$ & $1.14(0.87-1.50)$ & 5 \\
\hline$<60$ & $1.32(0.98-1.77)$ & 4 \\
\hline $60-79.9$ & $1.14(0.85-1.51)$ & 4 \\
\hline$\geq 80$ & $1.19(0.49-2.94)$ & 1 \\
\hline \multicolumn{3}{|l|}{ Stratified by TSH, mIU/L } \\
\hline $0.1-0.44$ & $0.62(0.21-1.86)$ & 1 \\
\hline$<0.1$ & $0.96(0.33-2.80)$ & 1 \\
\hline \multicolumn{3}{|l|}{ Adjustments } \\
\hline Adjusted analyses or matching & $1.20(1.02-1.42)$ & 9 \\
\hline Adjusted for cardiovascular risk factors & $1.18(0.94-1.49)$ & 6 \\
\hline \multicolumn{3}{|l|}{ Excluding studies } \\
\hline Exclusion of studies with antithyroid drug recipients & $1.18(0.98-1.41)$ & 7 \\
\hline Exclusion of studies with particular population [42] & $1.21(1.02-1.45)$ & 8 \\
\hline Subclinical hyperthyroidism and total mortality & 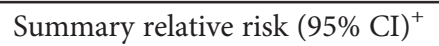 & Studies, $n$ \\
\hline \multicolumn{3}{|l|}{ Eligible study model } \\
\hline Random effects & $1.27(1.07-1.51)$ & 10 \\
\hline Fixed effects & $1.36(1.22-1.51)$ & 10 \\
\hline \multicolumn{3}{|l|}{ Stratified by mean age, y } \\
\hline$<65$ & $1.62(1.37-1.90)$ & 2 \\
\hline$\geq 65$ & $1.17(0.98-1.40)$ & 8 \\
\hline$<60$ & $1.62(1.37-1.90)$ & 2 \\
\hline $60-79.9$ & $1.18(0.96-1.44)$ & 7 \\
\hline$\geq 80$ & $1.08(0.60-1.93)$ & 1 \\
\hline \multicolumn{3}{|l|}{ Stratified by TSH, mIU/L } \\
\hline $0.1-0.44$ & $0.45(0.12-1.76)$ & 1 \\
\hline$<0.1$ & $1.74(0.78-3.87)$ & 1 \\
\hline \multicolumn{3}{|l|}{ Adjustments } \\
\hline Adjusted analyses or matching & $1.27(1.07-1.51)$ & 10 \\
\hline Adjusted for cardiovascular risk factors & $1.23(0.94-1.63)$ & 5 \\
\hline \multicolumn{3}{|l|}{ Excluding studies } \\
\hline Exclusion of studies with antithyroid drug recipients & $1.26(1.04-1.53)$ & 8 \\
\hline Exclusion of studies with particular population [42] & $1.29(1.07-1.54)$ & 9 \\
\hline Subclinical hyperthyroidism and cardiovascular mortality & Summary relative risk $(95 \% \mathrm{CI})^{+}$ & Studies, $n$ \\
\hline \multicolumn{3}{|l|}{ Eligible study model } \\
\hline Random effects & $1.12(0.84-1.50)$ & 7 \\
\hline Fixed effects & $1.10(0.82-1.47)$ & 7 \\
\hline \multicolumn{3}{|l|}{ Stratified by mean age, y } \\
\hline$<65$ & $0.84(0.28-2.50)$ & 1 \\
\hline$\geq 65$ & $1.15(0.85-1.55)$ & 6 \\
\hline$<60$ & $0.84(0.28-2.50)$ & 1 \\
\hline $60-79.9$ & $1.15(0.84-1.58)$ & 5 \\
\hline$\geq 80$ & $1.11(0.39-3.17)$ & 1 \\
\hline
\end{tabular}


TABLE 3: Continued.

\begin{tabular}{lll}
\hline Stratified by TSH, mIU/L & & \\
$0.1-0.44$ & $0.47(0.07-3.27)$ & 1 \\
$<0.1$ & $2.16(0.74-6.34)$ & \\
Adjustments & $1.12(0.84-1.50)$ & 7 \\
Adjusted analyses or matching & $0.98(0.65-1.47)$ \\
Adjusted for cardiovascular risk factors & & 4 \\
Excluding studies & $1.13(0.81-1.58)$ & 5 \\
Exclusion of studies with antithyroid drug recipients & $1.12(0.83-1.52)$ \\
Exclusion of studies with particular population [42] & 6 \\
\hline
\end{tabular}

CHD: coronary heart disease; TSH: thyroid-stimulating hormone. ${ }^{+}$Relative risk from meta-analysis using random-effects model.

\section{Discussion}

This meta-analysis was a systematic literature review for prospective cohort studies to ensure the relationship of SCTD and cardiovascular outcomes. We included 16 prospective cohort studies, and we found that subclinical hypothyroidism was likely associated with increased risk of CHD mortality and subclinical hyperthyroidism was likely associated with increased risk of $\mathrm{CHD}$, CHD mortality, and total mortality. Although the discovery of SCTD might increase the risk of other cardiovascular outcomes, the difference was not significant. For subclinical hypothyroidism, the quality of evidence was moderate for total and CHD mortality, low for $\mathrm{CHD}$, cardiovascular mortality, heart failure, and atrial fibrillation (Supplemental Material Table 3). For subclinical hyperthyroidism, the quality of evidence was moderate for CHD, CHD mortality, total, and cardiovascular mortality and low for heart failure and atrial fibrillation (Supplemental Material Table 4).

For the association between subclinical hypothyroidism and $\mathrm{CHD}$, total, and cardiovascular mortality, our results are consistent with previous meta-analyses [27, 28]. Although some meta-analyses [29, 45] reported significant associations between subclinical hypothyroidism and CHD, previous meta-analyses included case-control and crosssection studies, which could not accurately reflect a causeand-effect relationship. Recent meta-analysis showed that the association between CHD and subclinical hypothyroidism was TSH related, and this phenomenon was significantly elevated in individuals with TSH levels of $10 \mathrm{mIU} / \mathrm{L}$ or greater [27]. However, this was not confirmed by our analysis. For TSH values over $10 \mathrm{mIU} / \mathrm{L}$, our meta-analysis showed no significant association $(\mathrm{RR}=1.38 ; 95 \% \mathrm{CI}, 0.68-2.78)$ between subclinical hypothyroidism and $\mathrm{CHD}$ based on 12,731 participants. However, Rodondi et al. [27] found a positive results in $\mathrm{CHD}(\mathrm{HR}=1.89$; 95\% CI, 1.28-2.80) based on 235 participants, which was at odds with our metaanalysis. Our result was based on perspective cohort studies with NOS score $>7$, so we believed that our result was more reliable because of low risk of bias, large sample size, and statistical power. For TSH values below $10 \mathrm{mIU} / \mathrm{L}$, our meta-analysis got a similar result with previous metaanalyses [27, 28]. In overall pooled data, we found high heterogeneity for CHD. To detect the issue of heterogeneity, we performed subgroup and sensitivity analyses. Heterogeneity was reduced by excluding studies that included thyroid hormone recipients.

Our study found that in patients with mean age $<65$ years, subclinical hypothyroidism significantly increased the risk of $\mathrm{CHD}$, CHD mortality, and cardiovascular mortality. However, these results were not obtained in patients aged $>80$ years on average. Owing to the relatively few studies, the results should be interpreted carefully and confirmed by further studies. We found that subclinical hypothyroidism was associated with a slightly, but not significantly, increased risk of atrial fibrillation and heart failure. However, the results should be considered carefully owing to the small sample size.

For the associations between subclinical hyperthyroidism and cardiovascular outcomes, our study demonstrated that the risk of $\mathrm{CHD}, \mathrm{CHD}$ mortality, and total mortality was increased in patients with subclinical hyperthyroidism, and the difference was significant. Three possible mechanisms have been reported to explain this association. Firstly, insulin resistance is the major risk factors for cardiovascular disease [46]. Insulin sensitivity was significantly decreased in patients with subclinical hyperthyroidism, thereby increasing the risk of cardiovascular events [47-49]. Secondly, the levels of plasma fibrinogen and Ddimer in subjects with subclinical hyperthyroidism were higher than those with euthyroidism [50]. Elevated fibrinogen is an independent risk factor for coronary artery disease, and elevated serum D-dimer may increase the risk of future myocardial infarction. Lastly, several cardiovascular mechanisms have been reported in subclinical hyperthyroidism, such as increasing heart rate [17], left ventricular mass [18], being prone to endothelial dysfunction [19], and left ventricular diastolic dysfunction [20], causing cardiovascular changes in morphology and function. One study has reported that subclinical hyperthyroidism participants with decreased serum TSH levels had higher intima media thickness (IMT) than those with euthyroidism [51].

Our study found an increased CHD mortality (three studies) and total mortality (two studies) in patients with subclinical hyperthyroidism $<65$ years. However, this 


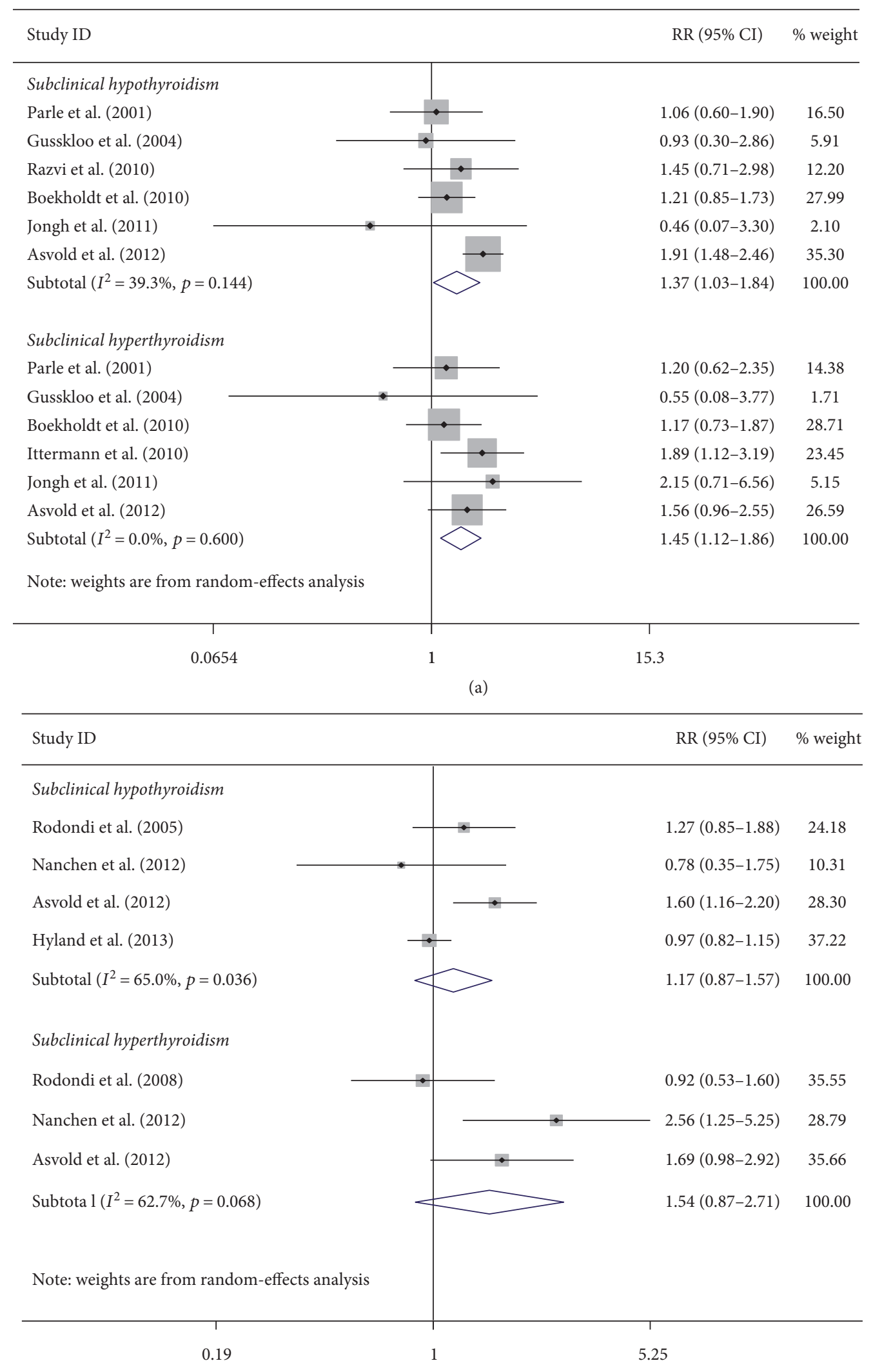

(b)

Figure 3: Continued. 


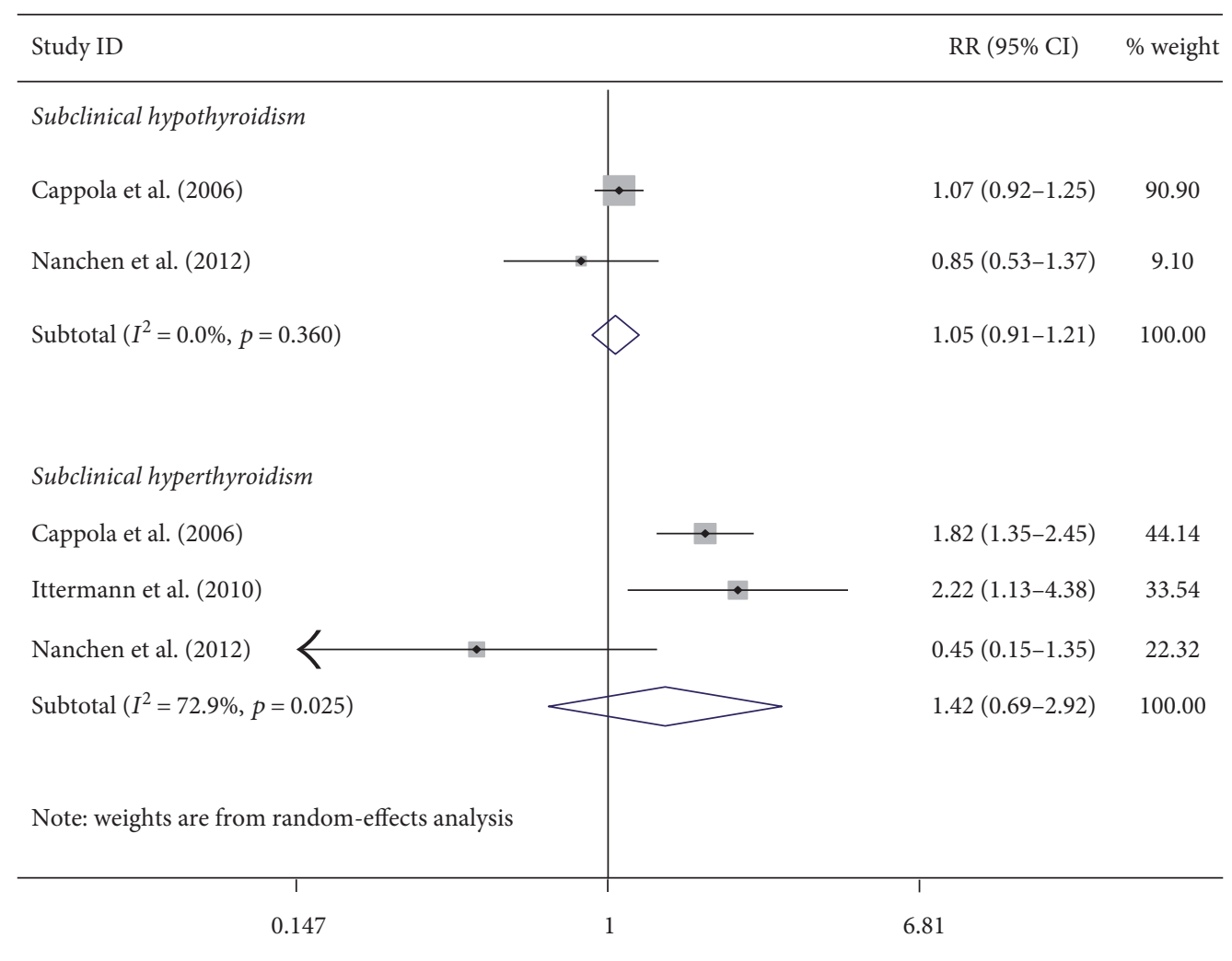

(c)

FIgURE 3: Forest plots for subclinical thyroid dysfunction. (a) Forest plots for subclinical thyroid dysfunction and CHD mortality; (b) forest plots for subclinical thyroid dysfunction and risk of heart failure; (c) forest plots for subclinical thyroid dysfunction and risk of atrial fibrillation.

potential difference should be interpreted with caution, because there were only few studies reported these outcomes. Selective bias might be existing in the other studies, which could contribute to a misleading result. On the other hand, the duration of follow-up could also influence the result. An increased total mortality was observed in a study of people $>60$ years with subclinical hyperthyroidism, during the first five years of follow-up [43]. Another prospective observational study from Brazil found that all-cause and cardiovascular mortality were also significantly higher in individuals with subclinical hyperthyroidism, during a 7.5-year follow-up [22]. However, in these two studies, the increased mortality emerged during the $<10$-year follow-up, whereas it was not observed over the full follow-up period of 10 years [22, 43]. In our study, the follow-up duration ranged from 8.5 to 12.3 years in $\mathrm{CHD}$ mortality and 8.5 to 10.6 years in total mortality.

In the age subgroup analysis, in those mean age $<65$ years, the risk of $\mathrm{CHD}, \mathrm{CHD}$ mortality, cardiovascular mortality, and total mortality is higher than for those of average age $\geq 65$ years. This showed that age is a risk factor for cardiovascular outcomes, suggesting that subclinical thyroid dysfunction in patients with mean age $<65$ years should pay attention to primary and secondary prevention of cardiovascular disease. The risk of cardiovascular outcomes in patients of average age $\geq 80$ years was relatively low, possibly owing to other diseases such as cancer, mortality, or other diseases.

Subclinical thyroid dysfunction is a common endocrine and metabolic disease, characterized by abnormal TSH level. Subclinical thyroid dysfunction has become more easily to be found in the population along with the continuous improvement of detection. However, the clinical symptoms of subclinical thyroid dysfunction are slight and uneven and can easily go unnoticed which might lead to controversy on screening and treatment of subclinical thyroid dysfunction in practice $[8,52]$. Our study found that subclinical thyroid dysfunction may increase cardiovascular risk; however, unlike dyslipidemia, diabetes mellitus, and hypertension, it may have a greater impact on cardiovascular risk. Clinical studies have shown that treatment of subclinical hypothyroidism is beneficial to endothelial function [16] and carotid arterial IMT [53], as these are early signs of atherosclerosis. Levothyroxine is commonly recommended as appropriate when the TSH concentration is $\geq 10 \mathrm{mIU} / \mathrm{L}$. The recent available guidelines for the management of patients with serum TSH $<10 \mathrm{mIU} / \mathrm{L}$ should consider the age of the patient, associated risk factors, and comorbid conditions [54]. Treatment could be considered in patients aged $>65$ years with TSH levels from 0.1 to $0.39 \mathrm{mIU} / \mathrm{L}$ and might also be reasonable in symptomatic patients aged $<65$ years with TSH levels $<0.1 \mathrm{mIU} / \mathrm{L}$ [55]. 
TABLE 4: Stratified and sensitivity analysis of the subclinical thyroid dysfunction.

\begin{tabular}{|c|c|c|}
\hline Subclinical hypothyroidism and CHD mortality & Summary relative risk $(95 \% \mathrm{CI})^{+}$ & Studies, $n$ \\
\hline \multicolumn{3}{|l|}{ Eligible study model } \\
\hline Random effects & $1.37(1.03-1.84)$ & 6 \\
\hline Fixed effects & $1.47(1.22-1.77)$ & 6 \\
\hline \multicolumn{3}{|l|}{ Stratified by mean age, y } \\
\hline$<65$ & $1.54(1.11-2.15)$ & 3 \\
\hline$\geq 65$ & $0.98(0.60-1.62)$ & 3 \\
\hline$<60$ & $1.54(1.11-2.15)$ & 3 \\
\hline $60-79.9$ & $1.00(0.57-1.74)$ & 2 \\
\hline$\geq 80$ & $0.93(0.30-2.86)$ & 1 \\
\hline \multicolumn{3}{|l|}{ Adjustments } \\
\hline Adjusted analyses or matching & $1.37(1.03-1.84)$ & 6 \\
\hline Adjusted for cardiovascular risk factors & $1.18(0.83-1.67)$ & 2 \\
\hline \multicolumn{3}{|l|}{ Excluding studies } \\
\hline Exclusion of studies with thyroid hormone recipients & $1.17(0.89-1.53)$ & 5 \\
\hline Exclusion of studies with particular population [42] & $1.40(1.03-1.91)$ & 5 \\
\hline Subclinical hyperthyroidism and CHD mortality & 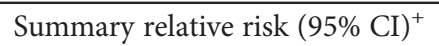 & Studies, $n$ \\
\hline \multicolumn{3}{|l|}{ Eligible study model } \\
\hline Random effects & $1.45(1.12-1.86)$ & 6 \\
\hline Fixed effects & $1.42(1.11-1.83)$ & 6 \\
\hline \multicolumn{3}{|l|}{ Stratified by mean age, y } \\
\hline$<65$ & $1.49(1.12-1.98)$ & 3 \\
\hline$\geq 65$ & $1.30(0.75-2.25)$ & 3 \\
\hline$<60$ & $1.49(1.12-1.98)$ & 3 \\
\hline $60-79.9$ & $1.40(0.79-2.49)$ & 2 \\
\hline$\geq 80$ & $0.55(0.08-3.77)$ & 1 \\
\hline \multicolumn{3}{|l|}{ Adjustments } \\
\hline Adjusted analyses or matching & $1.45(1.12-1.86)$ & 6 \\
\hline Adjusted for cardiovascular risk factors & $1.52(1.06-2.18)$ & 3 \\
\hline \multicolumn{3}{|l|}{ Excluding studies } \\
\hline Exclusion of studies with thyroid hormone recipients & $1.41(1.05-1.89)$ & 5 \\
\hline Exclusion of studies with particular population [42] & $1.47(1.14-1.90)$ & 5 \\
\hline
\end{tabular}

${ }^{+}$Relative risk from meta-analysis using random-effects model.

Our study has several strengths. Firstly, we conducted a systematic literature search for potential studies, without language restrictions, as broadly as possible to include all studies related to the research topic. Secondly, we included only prospective cohort studies with NOS score $\geq 7$ points, which could ensure the quality of our study. Besides, we assessed the quality of evidence using GRADE approach, which could reflect our confidence in the credibility of the results. Thirdly, we conducted subgroup and sensitivity analyses to various outcome measures.

Our analysis also has some limitations. Firstly, all data from this study were derived from observational studies, so the study may be affected by confounding factors and the results should be interpreted with caution. Secondly, thyroid function testing was measured at baseline, and we have no data on the possible progression from subclinical to overt dysfunction. In addition, different TSH cutoff levels in the original study, definitions of $\mathrm{CHD}$, and diagnostic criteria are not uniform, and the adjustment of the confounding factors were different.

\section{Conclusion}

In summary, our meta-analysis showed that subclinical hypothyroidism is likely associated with an increased risk of CHD mortality, and subclinical hyperthyroidism is likely associated with increased risk of CHD, CHD mortality, and total mortality. Although there are some confounders in this study, for example, the associations found in most cases are much weak, varied follow-up duration and selection bias were suspected in most studies, which may weaken the results of this meta-analysis, we believe that the findings in this meta-analysis provide useful information for stakeholders with an interest in the outcomes of patients with subclinical thyroid dysfunction. 


\section{Conflicts of Interest}

The authors declare that there is no conflict of interest that could be perceived as prejudicing the impartiality of the research reported.

\section{Authors' Contributions}

Limin Tian conceived and designed the experiments. Jing Sun performed the experiments. Jing Sun, Yuan Fang, and Ruifei Yang analyzed the data. Jing Sun wrote the paper. Limin Tian, Kehu Yang, and Liang Yao offered suggestions. Jing Sun and Liang Yao contributed equally to this work.

\section{Acknowledgments}

The authors thank Kehu Yang, Yaolong Chen, and Jinhui Tian (Evidence-Based Medicine Center of Lanzhou University) for their help and support to the methodology and meta-analysis process.

\section{References}

[1] D. S. Cooper and B. Biondi, "Subclinical thyroid disease," Lancet, vol. 379, pp. 1142-1154, 2012.

[2] B. Biondi and D. S. Cooper, "The clinical significance of subclinical thyroid dysfunction," Endocrine Reviews, vol. 29, pp. 76-131, 2008.

[3] J. V. Hennessey and R. Espaillat, "Diagnosis and management of subclinical hypothyroidism in elderly adults: a review of the literature," Journal of the American Geriatrics Society, vol. 63, pp. 1663-1673, 2015.

[4] A. L. Mitchell and S. H. Pearce, "Subclinical hyperthyroidism: first do no harm," Clinical Endocrinology, vol. 85, pp. 15-16, 2016.

[5] S. M. Boekholdt, S. M. Titan, W. M. Wiersinga et al., "Initial thyroid status and cardiovascular risk factors: the EPICNorfolk prospective population study," Clinical Endocrinology, vol. 72, pp. 404-410, 2010.

[6] J. P. Walsh, A. P. Bremner, M. K. Bulsara et al., "Subclinical thyroid dysfunction and blood pressure: a community-based study," Clinical Endocrinology, vol. 65, pp. 486-491, 2006.

[7] G. J. Canaris, N. R. Manowitz, G. Mayor, and E. C. Ridgway, "The Colorado thyroid disease prevalence study," Archives of Internal Medicine, vol. 160, pp. 526-534, 2000.

[8] J. B. Rugge, C. Bougatsos, and R. Chou, "Screening for and treatment of thyroid dysfunction: an evidence review for the U.S. Preventive Services Task Force," Archives of Internal Medicine, vol. 162, pp. 35-45, 2015.

[9] H. Vargas-Uricoechea, A. Bonelo-Perdomo, and C. H. SierraTorres, "Effects of thyroid hormones on the heart," Clínica e Investigación en Arteriosclerosis, vol. 26, pp. 296-309, 2014.

[10] J. Wu, Y. Tao, H. Gu, and J. Sui, "Association between cardiovascular risk factors and serum thyrotropin concentration among healthy Chinese subjects and subjects with unsuspected subclinical hypothyroidism," Clinical Laboratory, vol. 62, pp. 807-814, 2016.

[11] M. Tadic, V. Celic, C. Cuspidi, S. Ilic, V. Zivanovic, and T. Marjanovic, "How does subclinical hyperthyroidism affect right heart function and mechanics?," Journal of Ultrasound in Medicine, vol. 35, pp. 287-295, 2016.
[12] S. Humerah, A. Siddiqui, and H. F. Khan, "Pattern of altered lipid profile in patients with subclinical and clinical hypothyroidism and its correlation with body mass index," Journal of the College of Physicians and Surgeons Pakistan, vol. 26, pp. 463-466, 2016.

[13] N. Yang, Z. Yao, L. Miao et al., "Novel clinical evidence of an association between homocysteine and insulin resistance in patients with hypothyroidism or subclinical hypothyroidism," PLoS One, vol. 10, article e0125922, 2015.

[14] A. N. Syamsunder, P. Pal, G. K. Pal et al., "Decreased baroreflex sensitivity is linked to the atherogenic index, retrograde inflammation, and oxidative stress in subclinical hypothyroidism," Endocrinology, vol. 42, no. 1, pp. 49-58, 2017.

[15] P. J. Owen, C. Rajiv, D. Vinereanu, T. Mathew, A. G. Fraser, and J. H. Lazarus, "Subclinical hypothyroidism, arterial stiffness, and myocardial reserve," The Journal of Clinical Endocrinology and Metabolism, vol. 91, pp. 21262132, 2006.

[16] N. Niknam, N. Khalili, E. Khosravi, and M. Nourbakhsh, "Endothelial dysfunction in patients with subclinical hypothyroidism and the effects of treatment with levothyroxine," Advanced Biomedical Research, vol. 5, p. 38, 2016.

[17] G. Kaminski, D. Michalkiewicz, K. Makowski et al., "Prospective echocardiographic evaluation of patients with endogenous subclinical hyperthyroidism and after restoring euthyroidism," Clinical Endocrinology, vol. 74, pp. 501-507, 2011.

[18] P. D. Mark, M. Andreassen, C. L. Petersen, A. Kjaer, and J. Faber, "Treatment of subclinical hyperthyroidism: effect on left ventricular mass and function of the heart using magnetic resonance imaging technique," Endocrine Connections, vol. 4, pp. 37-42, 2015.

[19] A. Poplawska-Kita, K. Siewko, B. Telejko et al., "The changes in the endothelial function and haemostatic and inflammatory parameters in subclinical and overt hyperthyroidism," International Journal of Endocrinology, vol. 2013, Article ID 981638, 7 pages, 2013.

[20] M. Tadic, S. Ilic, C. Cuspidi, T. Marjanovic, and V. Celic, "Subclinical hyperthyroidism impacts left ventricular deformation: 2D and 3D echocardiographic study," Scandinavian Cardiovascular Journal, vol. 49, pp. 74-81, 2015.

[21] R. T. Jongh, P. Lips, N. M. van Schoor et al., "Endogenous subclinical thyroid disorders, physical and cognitive function, depression, and mortality in older individuals," European Journal of Endocrinology, vol. 165, pp. 545554, 2011.

[22] J. A. Sgarbi, L. K. Matsumura, T. S. Kasamatsu, S. R. Ferreira, and R. M. Maciel, "Subclinical thyroid dysfunctions are independent risk factors for mortality in a 7.5-year follow-up: the Japanese-Brazilian thyroid study," European Journal of Endocrinology, vol. 162, pp. 569-577, 2010.

[23] A. R. Cappola, L. P. Fried, A. M. Arnold et al., "Thyroid status, cardiovascular risk, and mortality in older adults: the cardiovascular health study," The Journal of the American Medical Association, vol. 295, pp. 1033-1041, 2006.

[24] J. P. Walsh, A. P. Bremner, M. K. Bulsara et al., "Subclinical thyroid dysfunction as a risk factor for cardiovascular disease," Archives of Internal Medicine, vol. 165, pp. 24672472, 2005.

[25] L. B. Yang, D. Q. Jiang, W. B. Qi et al., "Subclinical hyperthyroidism and the risk of cardiovascular events and all-cause mortality: an updated meta-analysis of cohort 
studies," European Journal of Endocrinology, vol. 167, pp. 75-84, 2012.

[26] T. H. Collet, J. Gussekloo, D. C. Bauer et al., "Subclinical hyperthyroidism and the risk of coronary heart disease and mortality," Archives of Internal Medicine, vol. 172, pp. 799809, 2012.

[27] N. Rodondi, W. P. den Elzen, D. C. Bauer et al., "Subclinical hypothyroidism and the risk of coronary heart disease and mortality," The Journal of the American Medical Association, vol. 304, pp. 1365-1374, 2010.

[28] N. Ochs, R. Auer, D. C. Bauer et al., "Meta-analysis: subclinical thyroid dysfunction and the risk for coronary heart disease and mortality," Annals of Internal Medicine, vol. 148, pp. 832-845, 2008.

[29] S. Singh, J. Duggal, J. Molnar, F. Maldonado, C. P. Barsano, and R. Arora, "Impact of subclinical thyroid disorders on coronary heart disease, cardiovascular and all-cause mortality: a meta-analysis," International Journal of Cardiology, vol. 125, pp. 41-48, 2008.

[30] P. Haentjens, M. A. Van, K. Poppe, and B. Velkeniers, "Subclinical thyroid dysfunction and mortality: an estimate of relative and absolute excess all-cause mortality based on time-to-event data from cohort studies," European Journal of Endocrinology, vol. 159, pp. 329-341, 2008.

[31] K. A. Hyland, A. M. Arnold, J. S. Lee, and A. R. Cappola, "Persistent subclinical hypothyroidism and cardiovascular risk in the elderly: the cardiovascular health study," The Journal of Clinical Endocrinology and Metabolism, vol. 98, pp. 533-540, 2013.

[32] G. Ceresini, G. P. Ceda, F. Lauretani et al., "Thyroid status and 6-year mortality in elderly people living in a mildly iodine-deficient area: the aging in the Chianti area study," Journal of the American Geriatrics Society, vol. 61, pp. 868874, 2013.

[33] D. Nanchen, J. Gussekloo, R. G. Westendorp et al., "Subclinical thyroid dysfunction and the risk of heart failure in older persons at high cardiovascular risk," The Journal of Clinical Endocrinology and Metabolism, vol. 97, pp. 852861, 2012.

[34] B. O. Asvold, T. Bjoro, C. Platou, and L. J. Vatten, "Thyroid function and the risk of coronary heart disease: 12-year follow-up of the HUNT study in Norway," Clinical Endocrinology, vol. 77, pp. 911-917, 2012.

[35] M. Schultz, C. Kistorp, I. Raymond et al., "Cardiovascular events in thyroid disease: a population based, prospective study," Hormone and Metabolic Research, vol. 43, pp. 653$659,2011$.

[36] A. Stang, "Critical evaluation of the Newcastle-Ottawa scale for the assessment of the quality of nonrandomized studies in meta-analyses," European Journal of Epidemiology, vol. 25, pp. 603-605, 2010.

[37] S. E. Canfield and P. Dahm, "Rating the quality of evidence and the strength of recommendations using GRADE," World Journal of Urology, vol. 29, pp. 311-317, 2011.

[38] S. Razvi, J. U. Weaver, M. P. Vanderpump, and S. H. Pearce, "The incidence of ischemic heart disease and mortality in people with subclinical hypothyroidism: reanalysis of the Whickham survey cohort," The Journal of Clinical Endocrinology and Metabolism, vol. 95, pp. 1734-1740, 2010.

[39] N. Rodondi, D. C. Bauer, A. R. Cappola et al., "Subclinical thyroid dysfunction, cardiac function, and the risk of heart failure - the cardiovascular health study," Journal of the American College of Cardiology, vol. 52, pp. 1152-1159, 2008.

[40] D. C. Bauer, N. Rodondi, K. L. Stone, and T. A. Hillier, "Thyroid hormone use, hyperthyroidism and mortality in older women," The American Journal of Medicine, vol. 120, pp. 343-349, 2007.

[41] N. Rodondi, A. B. Newman, E. Vittinghoff et al., "Subclinical hypothyroidism and the risk of heart failure, other cardiovascular events, and death," Archives of Internal Medicine, vol. 165, pp. 2460-2466, 2005.

[42] J. Gussekloo, E. van Exel, A. J. de Craen, A. E. Meinders, M. Frölich, and R. G. Westendorp, "Thyroid status, disability and cognitive function, and survival in old age," The Journal of the American Medical Association, vol. 292, pp. 25912599, 2004.

[43] J. V. Parle, P. Maisonneuve, M. C. Sheppard, P. Boyle, and J. A. Franklyn, "Prediction of all-cause and cardiovascular mortality in elderly people from one low serum thyrotropin result: a 10-year cohort study," Lancet, vol. 358, pp. 861865, 2001.

[44] T. Ittermann, R. Haring, S. Sauer et al., "Decreased serum TSH levels are not associated with mortality in the adult northeast German population," European Journal of Endocrinology, vol. 162, pp. 579-585, 2010.

[45] N. Rodondi, D. Aujesky, E. Vittinghoff, J. Cornuz, and D. C. Bauer, "Subclinical hypothyroidism and the risk of coronary heart disease: a meta-analysis," The American Journal of Medicine, vol. 119, pp. 541-551, 2006.

[46] M. Laakso, "Is insulin resistance a feature of or a primary risk factor for cardiovascular disease?," Current Diabetes Reports, vol. 15, no. 12, p. 105, 2015.

[47] E. Maratou, D. J. Hadjidakis, M. Peppa et al., "Studies of insulin resistance in patients with clinical and subclinical hyperthyroidism," European Journal of Endocrinology, vol. 163, pp. 625-630, 2010.

[48] D. G. Yavuz, M. Yuksel, O. Deyneli, Y. Ozen, H. Aydin, and S. Akalin, "Association of serum paraoxonase activity with insulin sensitivity and oxidative stress in hyperthyroid and TSH-suppressed nodular goitre patients," Clinical Endocrinology, vol. 61, pp. 515-521, 2004.

[49] A. Roos, S. J. Bakker, T. P. Links, R. O. Gans, and B. H. Wolffenbuttel, "Thyroid function is associated with components of the metabolic syndrome in euthyroid subjects," The Journal of Clinical Endocrinology and Metabolism, vol. 92, pp. 491-496, 2007.

[50] E. Coban and M. Aydemir, "Levels of plasma fibrinogen and D-dimer in subjects with subclinical hyperthyroidism," Medical Science Monitor, vol. 14, pp. CR42-CR46, 2008.

[51] H. Volzke, D. M. Robinson, U. Schminke et al., "Thyroid function and carotid wall thickness," The Journal of Clinical Endocrinology and Metabolism, vol. 89, pp. 2145-2149, 2004.

[52] R. B. Burns, C. K. Bates, P. Hartzband, and G. W. Smetana, "Should we treat for subclinical hypothyroidism?: grand rounds discussion from Beth Israel Deaconess Medical Center," Annals of Internal Medicine, vol. 164, pp. 764-770, 2016.

[53] S. K. Kim, S. H. Kim, K. S. Park, S. W. Park, and Y. W. Cho, "Regression of the increased common carotid artery-intima media thickness in subclinical hypothyroidism after thyroid hormone replacement," Endocrine Journal, vol. 56, pp. 753 $758,2009$. 
[54] Z. Javed and T. Sathyapalan, "Levothyroxine treatment of mild subclinical hypothyroidism: a review of potential risks and benefits," Therapeutic Advances in Endocrinology and Metabolism, vol. 7, pp. 12-23, 2016.

[55] B. Biondi, L. Bartalena, D. S. Cooper, L. Hegedus, P. Laurberg, and G. J. Kahaly, "The 2015 European Thyroid Association guidelines on diagnosis and treatment of endogenous subclinical hyperthyroidism," European Thyroid Journal, vol. 4, pp. 149-163, 2015. 


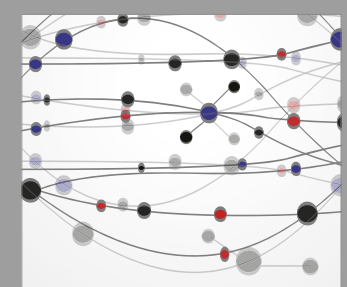

The Scientific World Journal
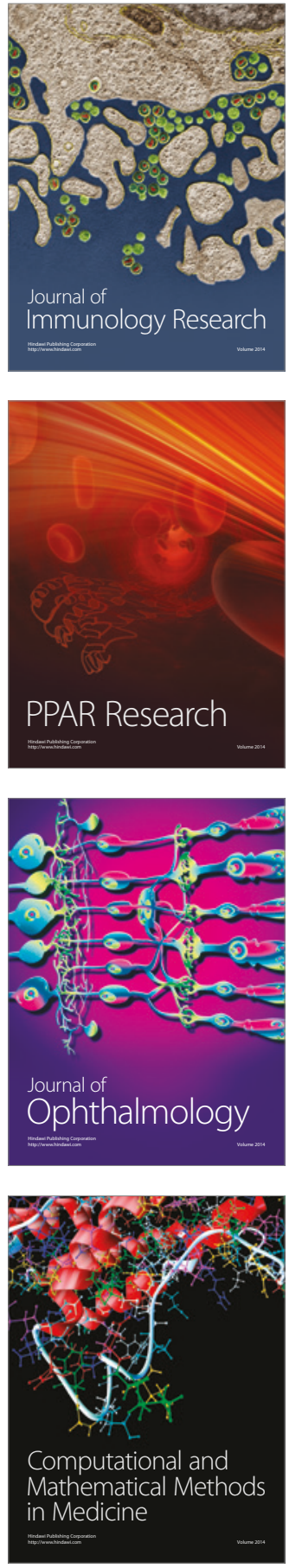

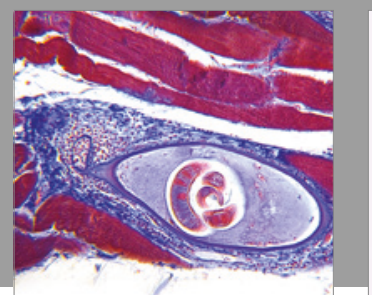

Gastroenterology Research and Practice
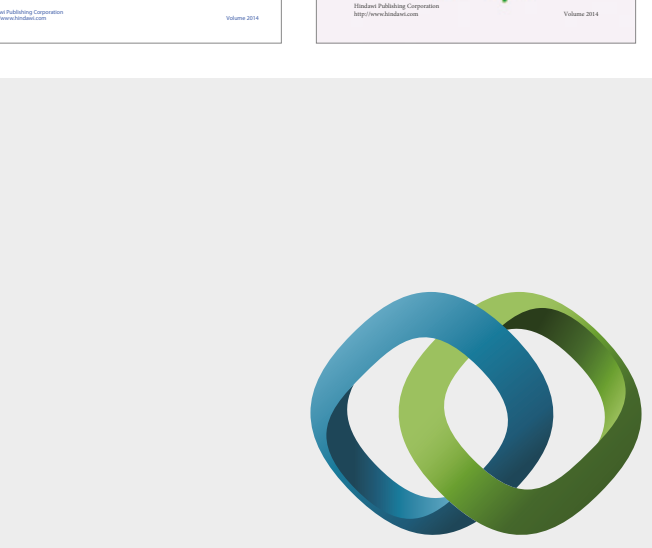

\section{Hindawi}

Submit your manuscripts at

https://www.hindawi.com
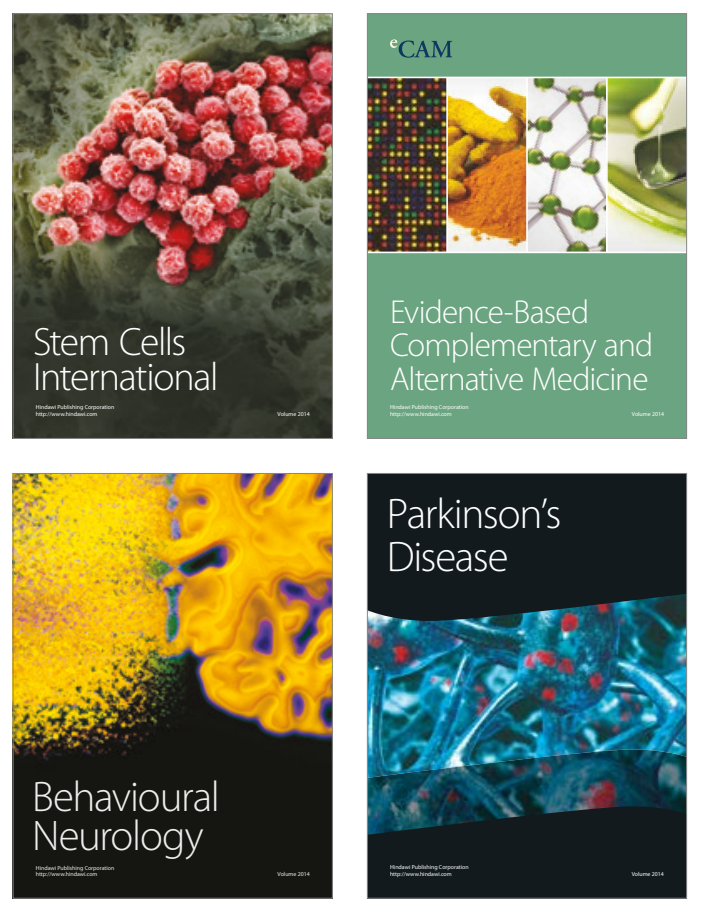
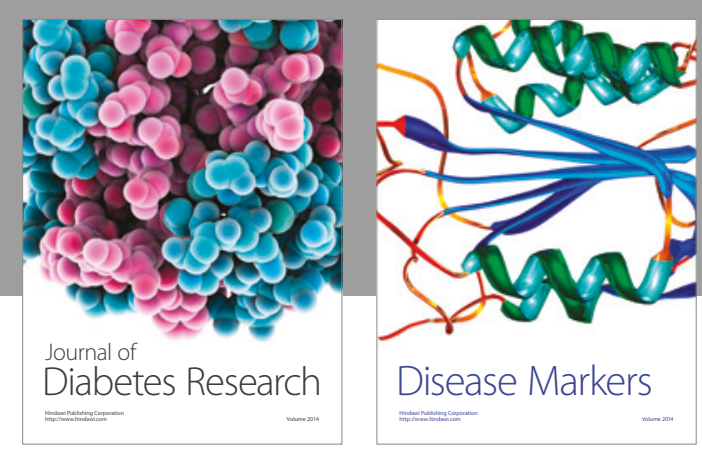

Disease Markers
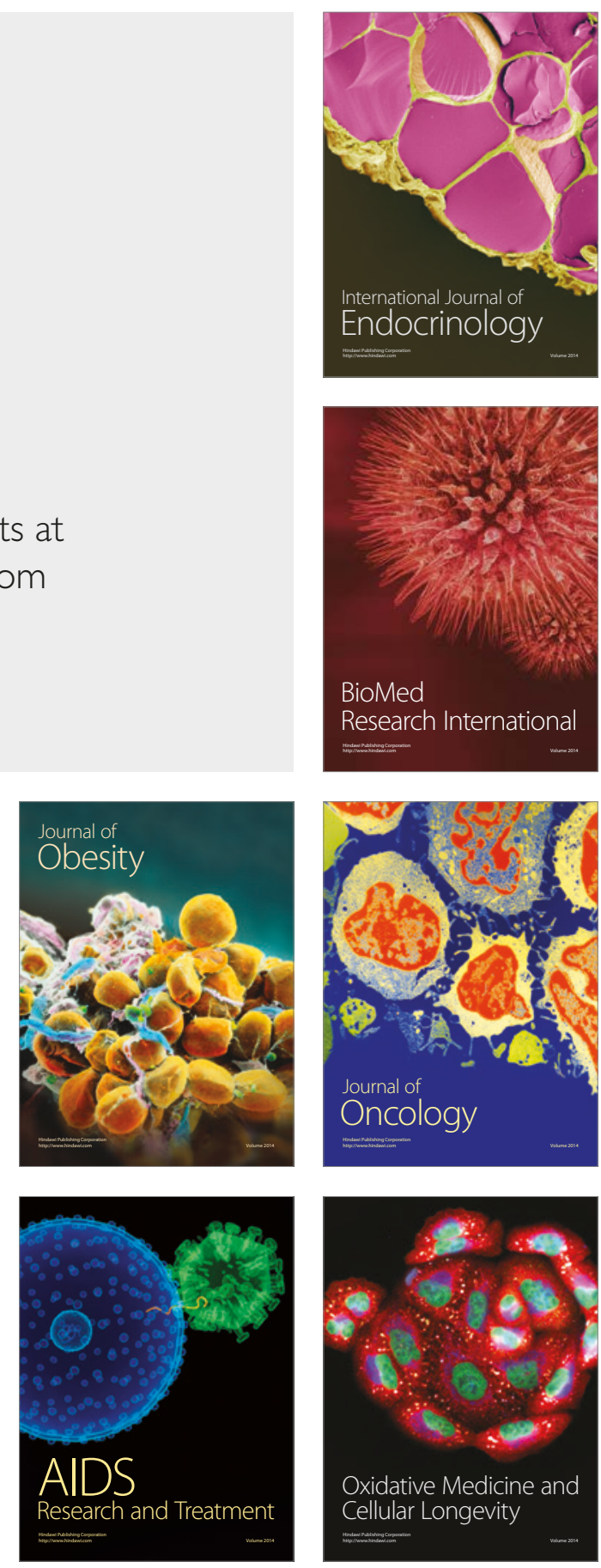